\title{
An Appeal for a Rational Approach to TMD and Orofacial Pain
}

\section{Harold F. Menchel}

Department of Prosthodontics, Nova Southeastern School of Dental Medicine, Ft. lauderdale Florida, USA

*Corresponding author: Harold F. Menchel, Adjunct Faculty, Department of Prosthodontics, Nova Southeastern School Of Dental Medicine Ft. lauderdale Florida, USA, Tel: 954-345-2264; E-mail: hmenchel@gmail.com

Rec date: Sept 4, 2014, Acc date: Sept 6, 2014, Pub date: Sept 8, 2014

Copyright: ( 2014 Menchel. This is an open-access article distributed under the terms of the Creative Commons Attribution License, which permits unrestricted use, distribution, and reproduction in any medium, provided the original author and source are credited

\section{Temporomandibular Disorders and Orofacial Pain}

This article is an appeal to all orofacial pain (OFP) practitioners, no matter what the philosophy they ascribe to, whether they are dentists or physicians, to put aside our differences and come to a unified approach in the field of TMD, oral, and head and neck pain. This would benefit all parties concerned.

I have practiced dentistry for over 35 years and now limit my practice to diagnosis and management of orofacial pain (OFP). I am involved with treating patients on a daily basis, teaching in the dental school, and instructing practicing dentists in OFP all over the world.

My observations, shared by many in the field are; Patients are not being treated with any consistent evidence based standard of care. Dentists do not have basic skills to diagnose and manage these patients, the public has no idea where to go to seek help, and insurers are not providing coverage [1].

This problem can and must be solved. This article outlines a rational approach for a solution.

My experience is:

New OFP patients have the following common presentation:

- They have seen a number of prior dentists/physicians (orthodontists, oral surgeons, otolaryngology, chiropractic etc.). Many have spent thousands of dollars with no benefit [2-5].

- They have been given no diagnosis other than "TMJ".

- Unfortunately most patients present with orthotics that are ill fitting, poorly adjusted, and have little chance of success. There are even reports of occlusal changes occurring with these splints [6]. The efficacy of splint therapy for TMD is still controversial $[3,4]$ and further research is needed with well-designed randomized controlled trials. However, there is still enough supporting evidence for use of stabilization splints to recommend their use.

- OFP patients have been treated with occlusal equilibration, orthodontics, TMJ surgery, with no benefit or often an increase in pain [7]. They have never had adequate reversible conservative therapy.

- Many patients have no insurance coverage for conservative orofacial pain management. These results in them not appointing due to financial limitation.

The majority of dentists that I instruct in dental school and continuing education:

- Lack the ability to diagnose orofacial pain and are unaware of the TMD research diagnostic criteria. (TMD/RDC) $[8,9]$.

- Approach these patients from only a limited and narrow perspective (mainly only an occlusal approach) [10].
- Have the perception that these patients are difficult, time, consuming and non-productive. Many dentists would prefer not to get involved and want to refer these patients.

- Many dentists lack the skills to deliver even a basic flat plane stabilization splint for patients needing this treatment.

- Many dentists graduate dental school having never placed a splint [11].

- Dentists do not know to whom to refer OFP patients. Many have expressed to me that there is no orofacial pain dentist in their areas.

The orofacial pain arena is variegated, with diverse, controversial and often conflicting opinions of how these patients should be evaluated and managed. It is not my intent to here enter into this debate but to appeal to all dentists and practitioners that emphasize OFP in their practices to at least agree on the following:

Although there has been some improvement, basic orofacial pain instruction in dental schools is still lacking. Graduating dentists must be able to:

- Understand the anatomy and physiology of the stomatognathic system in relation to OFP.

- Be able to make a diagnosis based on the TMD/RDC.

- Be able to make a well fitting, adjusted stabilization splint out of the proper materials, and to follow the patient as necessary.

- Understand which patients may be better served by referral to an orofacial pain dentist, if they choose not to treat them.

- Understanding the role of the OFP dentist and how to coordinate dental treatment of OFP patients.

Dentists do seek continuing education in OFP. What most seek is basics; accurate diagnostics, so they can deal with uncomplicated patients, knowing when to refer and who to refer to. They want to include TMD concerns into their comprehensive treatment plans, for more predictable treatment success.

My course comments and evaluations consistently reflect that dentists attending my courses have little interest in advanced imaging, advanced pharmacology of orofacial pain, Axis II (psychological aspects of OFP), advanced splint therapy, and advanced diagnostics. Most dentists do not want to treat headache patients or do extra-oral injections necessary with many OFP patients. I now avoid addressing these topics in depth in my introductory course, attempt to dispel myths about TMD and OFP and provide evidence based information that can be implemented immediately and easily in practice.

I do however encourage any dentists who have a greater interest in orofacial pain, to educate themselves as the highest level possible, so that they can better serve their patients. A standardized curriculum for these dentists approved and implemented by ADA continuing education recognition program (CERP) would be of great value. 
Page 2 of 2

As far as the profession, the public, and third party payers it is past due for establishment of a specialty in OFP [2,12]. Most dentists surveyed (85\%) would prefer to refer TMD patients to an OFP dentist. There presently is no mechanism for this or an understandable standard of care that referrers are aware of. Credentials for a specialty in OFP would be gained in a postgraduate residency in an institutional setting, either dental school or hospital residency. It is mandatory that this education be evidenced based. The present ADA CODA on OFP provides this framework. There are now 11 OFP programs in dental schools in the US awarding a masters certificate [13-15].

I understand the difficulty that the ADA or any organization would have with certification of dentists to be "grandfathered" in as specialists. This problem is not insurmountable with cooperation of the different TMD groups including the American Academy of Orofacial Pain and the American Alliance of TMD organizations, as well as any other interested party. In any event the grandfathering period would likely not extend beyond a few years and this issue would self-resolve over time.

Insurers would also have approved standard of care so that patients could be reimbursed for conservative therapy.

As with any specialty there is no restriction on any dentist treating OFP patients. The specialty is there to provide them assistance as needed.

The American Academy of Oral and Maxillofacial Surgeons (AAMOS) has established with many state insurers, that oral surgeons be the primary OFP providers. Although a minority of TMD patients can benefit from surgical intervention, the standard of care today is that less surgery and the least invasive surgery is now indicated for most TMD patients.

An informal survey of oral surgeons in my geographical area indicates that less than $10 \%$ of the surgeons agree to treat TMD in their practices (they refer to an OFP dentist), and only a handful perform TMJ surgery. The AAMOS website even states: "appropriate referral to other dental or medical specialists or a physical therapist may be made". This further supports the need for an OFP specialty to coordinate the interdisciplinary care these patients require.

In conclusion, this is an appeal for a rational evidenced cooperative approach to OFP. We must put aside our egos and biases for the benefit of our patients. We need to stop the dogma. I would hope that most of the medical and dental profession would agree that a specialty is needed.

The truth is that there still is a great deal that is not understood in the field of OFP, and further research is needed. New evidence is constantly challenging the way we practice. Because of this we should all treat patients as conservatively as possible in hopes that tomorrow we will gain more insight in how to better manage pain patients.

Until then it is our obligation is as I have outlined to present a unified cohesive effort to eliminate the unnecessary confusion, wasted time and expense and suffering of our patients. The time is now!

\section{References}

1. Insurance coverage for Temporomandibular Disorders Blue Cross Blue Shield Association.

2. Fricton J, Look JO (2000) Practice patterns for Orofacial pain disorders: A survey of General Dentists, specialists, and Orofacial Pain.

3. Wassell RW, Adams N, Kelly PJ (2006) The treatment of temporomandibular disorders with stabilizing splints in general dental practice: One-year follow-up. J Am Dent Assoc 137: 1089-1098.

4. Al-Ani MZ, Davies SJ, Gray RJ, Sloan P, Glenny AM (2004) Stabilization splint therapy for temporomandibular pain dysfunction syndrome. Cochrane Database Rev 2004: CD002778.

5. Ebrahim S, Montoya L, Carrasco-Labra A, Guyatt GH (2012) The effectiveness of splint therapy in patients with temporomandibular disorders. J Am Dent Assoc 143: 847-857.

6. Magdaleno F, Ginestal E (2010) Side effects of stabilization occlusal splints: a report of three cases and literature review. Cranio 28: 128-135.

7. Carlsson GE (2010) Some dogmas related to prosthodontics, temporomandibular disorders and occlusion. Acta Odontol Scand 68: 313-322.

8. Schiffman EL, Truelove EL, Ohrbach R, Anderson GC, John MT, et al. (2010) The research Diagnostic Criteria for Temporomandibular Disorders: Overview and methodology for Assessment of Validity. J Orofac Pain 24: 7-24.

9. Dworkin SF, LeResche L (1992) Research diagnostic criteria for temporomandibular disorders: review, criteria, examinations and specifications, critique. J Craniomandib Disord 6: 301-355.

10. Klasser GD, Greene CS (2007) Predoctoral teaching of temporomandibular disorders: a survey of U.S. and Canadian dental schools. J Am Dent Assoc 138: 231-237.

11. Okeson JP (2007) Growing into a new specialty: One person's perspective. Cranio 25: 229-231.

12. Greene CS, Stockstill J, Rinchuse D, Sanjivan K (2012) Orthodontics and Temporomandibular disorders: A curriculum proposal for postgraduate programs. Am J Orthod Dentofacial Orthop 142: 18-24.

13. Heir GM, Bassiur J, Branch M (2010) Core curriculum in orofacial pain .postgraduate orofacial pain programs in United States-based dental school and university-based programs. J Orofac Pain 24: 423-449.

14. Commission on Dental Accreditation and American Dental Association. Accreditation Standards for Advanced Education General Dentistry Education Programs in Orofacial Pain.

15. American Academy of Oral and Maxillofacial Surgery. 